\title{
A one-step electrospray-based technique for modulating morphology and surface properties of poly(lactide-co-glycolide) microparticles using Pluronics ${ }^{\circledR}$
}

\author{
This article was published in the following Dove Press journal: \\ International Journal of Nanomedicine \\ 25 September 2012 \\ Number of times this article has been viewed
}

\author{
Anushree Seth \\ Dhirendra S Katti \\ Department of Biological Sciences \\ and Bioengineering, Indian Institute \\ of Technology Kanpur, Kanpur, \\ Uttar Pradesh, India
}

Correspondence: Dhirendra S Katti Department of Biological Sciences and Bioengineering, Indian Institute of Technology Kanpur, Kanpur-2080I6, Uttar Pradesh, India

Tel +9l 5 I 22594028

$\mathrm{Fax}+915122594010$

Email dsk@iitk.ac.in

\begin{abstract}
The influence of morphology and surface properties on the therapeutic efficacy of degradable polymeric microparticles has not been well understood. One of the primary reasons for this is the limited ability to fabricate microparticles with controlled morphology and surface properties. Here, we report the electrospraying of blends of Pluronic ${ }^{\circledR}$ with poly(lactide-coglycolide) (PLGA) as a novel, one-step approach for the simultaneous modulation of morphology and surface properties of PLGA microparticles. Blending with Pluronic ${ }^{\circledR}$ altered the morphology from doughnut-shaped to smooth, spherical-shaped microparticles, and variation in the type of Pluronic ${ }^{\circledR}$ systematically modulated the surface properties of the microparticles. Hence, blending with Pluronic ${ }^{\circledR}$ can be a facile technique for the modulation of morphology and surface properties of electrosprayed PLGA microparticles.
\end{abstract}

Keywords: blending, hydrophobicity, microstructures, surface charge, surface modification

\section{Introduction}

Polymeric micro-/nanoparticles have been widely used for therapeutic applications such as delivery of drugs/genes/vaccines, imaging, and medical diagnostics. ${ }^{1-6}$ The properties that govern their efficacy in these applications include bulk properties (composition and degradation rate), surface properties (surface chemistry, charge, and hydrophobicity), size, and morphology. ${ }^{7}$ It has been demonstrated that the morphology of micro-/nanoparticles can influence biodistribution, cellular uptake, cell internalization pathway, and drug release profile. ${ }^{8-12}$ Similarly, surface charge and surface hydrophobicity have been shown to influence the stability of micro-/nanoparticle suspensions, in vivo blood circulation time, biodistribution, protein adsorption, cellular uptake, and immune response. ${ }^{13-16}$ However, the influence of morphology and surface properties has not been well understood due to the limited ability of existing micro-/nanoparticle preparation techniques to modulate these properties. For example, micro-/nanoparticle preparation techniques like emulsion solvent evaporation, nanoprecipitation, suspension polymerization, and spray drying usually lead to the generation of particles with spherical morphology with minimal control on modifying surface properties. In order to provide deeper insight into the influence of surface properties and morphology of micro-/nanoparticles on the aforementioned aspects, it is essential to have the ability to precisely modulate these properties. In this report, we propose a new electrospraybased strategy that is capable of simultaneously modulating the morphology and surface properties of polymeric microparticles in a single step. 
Electrospraying has been established as a simple and efficient technique that makes use of high electric potential to facilitate atomization of solutions to form dried solid micro-/nanoparticles. ${ }^{17-19}$ Poly(lactide-co-glycolide) (PLGA), polyhydroxybutyrate (PHB), poly(lactic acid) (PLA), and polycaprolactone (PCL) are examples of polymers that have been electrosprayed into micro-/nanoparticles for drug delivery applications. ${ }^{20-23}$ While these polymers are biocompatible and biodegradable, their hydrophobicity can lead to the formation of unstable suspensions. ${ }^{24}$ More specifically, in aqueous dispersions, strong hydrophobic-hydrophobic interactions lead to insufficient wetting and, as a consequence, agglomeration of hydrophobic particles. The agglomeration in turn can compromise utility as it can adversely affect degradation kinetics and cellular uptake. Hence, imparting surface hydrophilicity to hydrophobic particles can help in overcoming the aforementioned limitations.

Recently, surface hydrophilization of electrospun hydrophobic PLGA fibers has been reported via blending with hydrophilic polymer-Pluronic ${ }^{\circledR}$ (a diblock co-polymer with a central hydrophobic propylene oxide [PO] unit flanked by hydrophilic ethylene oxide [EO] units). ${ }^{25}$ Pluronics ${ }^{\circledR}$ tend to come to the surface when blended with hydrophobic polymer such as PLGA and impart colloidal stability to particles. ${ }^{25,26}$ Additionally, Pluronics ${ }^{\circledR}$ are known to act as biological response modifiers that can be advantageous in drug delivery applications and are available in varying hydrophiliclipophilic balances (HLB) as a consequence of variation in lengths of EO and PO chains. ${ }^{27-29}$ Hence, in this report, blending of hydrophobic PLGA 85:15 with a versatile class of polymer-Pluronic ${ }^{\circledR}$ was used as the strategy for surface modification of electrosprayed PLGA microparticles.

\section{Materials and methods}

\section{Materials}

Pluronic ${ }^{\circledR}$ F127 (EO-200 units, PO-65 units, HLB-22), Pluronic ${ }^{\circledR}$ P123 (EO-39 units, PO-69 units, HLB-8) and Pluronic ${ }^{\circledR}$ L121 (EO-10 units, PO-68 units, HLB-1), referred to as F127, P123, and L121 respectively, and PLGA 85:15 (Mw- 50,000-75,000) were procured from Sigma Aldrich (St Louis, MO). Tetrahydrofuran (THF) and dimethylformamide (DMF) (HPLC grade) were procured from Merck (India) Ltd.

\section{Particle preparation}

\section{Electrospraying}

Polymer solution (6\% PLGA in THF: DMF-1:3) contained in a syringe was allowed to flow through a needle (26 gauge) at a fixed flow rate of $0.15 \mathrm{~mL} / \mathrm{h}$ with the help of a syringe pump.
A positive potential of $20 \mathrm{kV}$ was applied at the tip of the needle using a high-voltage power supply (Glassman High Voltage Inc, High Bridge, NJ), and a grounded copper plate covered with an aluminum foil placed at a distance of $15 \mathrm{~cm}$ served as the collector. The microparticles deposited on the aluminum foil were then subjected to vacuum desiccation for 24 hours to facilitate removal of residual solvent. For blends, each of F127, P123, and L121 (5\% w/w of polymer or $0.3 \% \mathrm{w} / \mathrm{v})$ was added to $6 \%$ PLGA in THF:DMF (1:3) to prepare three separate solutions that were electrosprayed with fabrication parameters remaining unchanged. For the preparation of aqueous dispersions $5 \mathrm{~mL}$ of $1 \mathrm{mg} / \mathrm{mL}$ of microparticles in a glass vial were sonicated over an ice-bath at an amplitude of 10 for 2 cycles (ON for 10 seconds and OFF for 3 seconds).

\section{Particle characterizations Morphology and size}

Scanning electron microscopy (SEM) (Quanta 200; FEI, Hillsboro, OR) was used to analyze the morphology and size of microparticles. Average microparticle size was quantified using Image J (National Institutes of Health, Bethesda, MD) software wherein diameters of a minimum of 250 microparticles from 5 different SEM images were estimated to arrive at mean values.

\section{Surface charge}

Surface charge was quantified as zeta potential using a Zetasizer (NANO-ZS, ZEN3600; Malvern Instruments, Malvern, UK).

\section{Surface hydrophobicity}

Rose Bengal, a hydrophobic dye, was adsorbed onto the surface of the microparticles and the partitioning of the dye provided a measure of the hydrophobicity of the microparticles..$^{30} 1 \mathrm{mg}$, $2 \mathrm{mg}, 3 \mathrm{mg}$, and $4 \mathrm{mg}$ of microparticles were separately added to $1 \mathrm{~mL}$ of Rose Bengal solution in phosphate-buffered saline (pH 7.0, $10 \mu \mathrm{g} / \mathrm{mL}$ ) and were incubated along with a control solution (without microparticles) in an incubator shaker at $37^{\circ} \mathrm{C}$ and $110 \mathrm{rpm}$. After 24 hours, the solutions were centrifuged at 12,000 rpm for 10 minutes. The absorbance of the supernatant was measured at $540 \mathrm{~nm}$ using a Spectronic Helios Alpha UV-Visible Spectrophotometer (Thermo Electron Corporation, Madison, WI). Partition coefficient (PQ) was calculated using Equation 1.

$$
\mathrm{PQ}=\frac{\text { Absorbance of blank }- \text { Absorbance of supernatant }}{\text { Absorbance of blank }}
$$


Relative hydrophobicity of the microparticles was quantified as the slopes of straight lines obtained by plotting PQ against the weight of the microparticles.

\section{Surface chemistry}

$\mathrm{X}$-ray photoelectron spectroscopy (XPS) was performed to analyze the surface chemistry (qualitative and quantitative) of the microparticles using a PHI Quantera (Physical Electrons, Chanhassen, $\mathrm{MN}$ ) with a monochromated Al-Ko X-ray source. PHI Multipak software (Physical Electrons) was used for data analysis.

\section{Statistical analysis}

Results were presented as mean \pm standard deviation and $\mathrm{R}^{2}$ values were determined using linear regression. Statistical analysis was performed using analysis of covariance (ANCOVA) to test for difference between the slopes of lines and values of $P<0.05$ were considered to be statistically significant. All analyses were performed using GraphPad Prism software (GraphPad Software, Inc, La Jolla, CA).

\section{Results and discussion Influence of Pluronics ${ }^{\circledR}$ on morphology and dispersibility of microparticles}

Electrospraying of 6\% PLGA 85:15 in THF:DMF (1:3) led to formation of doughnut-shaped microparticles as shown in Figure 1A. When low concentrations of Pluronic ${ }^{\circledR}(5 \% \mathrm{w} / \mathrm{w}$ of polymer) were added to the PLGA solution, interestingly, the morphology of the microparticles was altered from doughnut to smooth, spherical shape. This effect was observed for all three types of Pluronics ${ }^{\circledR}$ (F127, P123, and L121) (Figure 1B-D). The alteration in morphology from doughnut-like to smooth, spherical-shaped microparticles can be attributed to a homogeneous redistribution of polymer chains in the presence of Pluronics $^{\circledR}$ that are amphiphilic polymeric surfactants. During electrospraying, the wet droplet ejects from the needle tip and undergoes evaporation; this homogeneous redistribution of polymer chains is speculated to cause the change to spherical morphology. It has also been reported that lowering of the Peclet number (which is inversely proportional to diffusivity) of the solution leads to the generation of smooth, spherical microparticles..$^{20}$ Pluronics ${ }^{\circledR}$, due to their lower molecular weight and surfactant properties, impart relatively higher molecular diffusivities that facilitate the lowering of the Peclet number of the solutions, which probably leads to the generation of smooth, spherical microparticles.

The hydrophobicity imparted by PLGA to the doughnutshaped microparticles lead to their agglomeration when

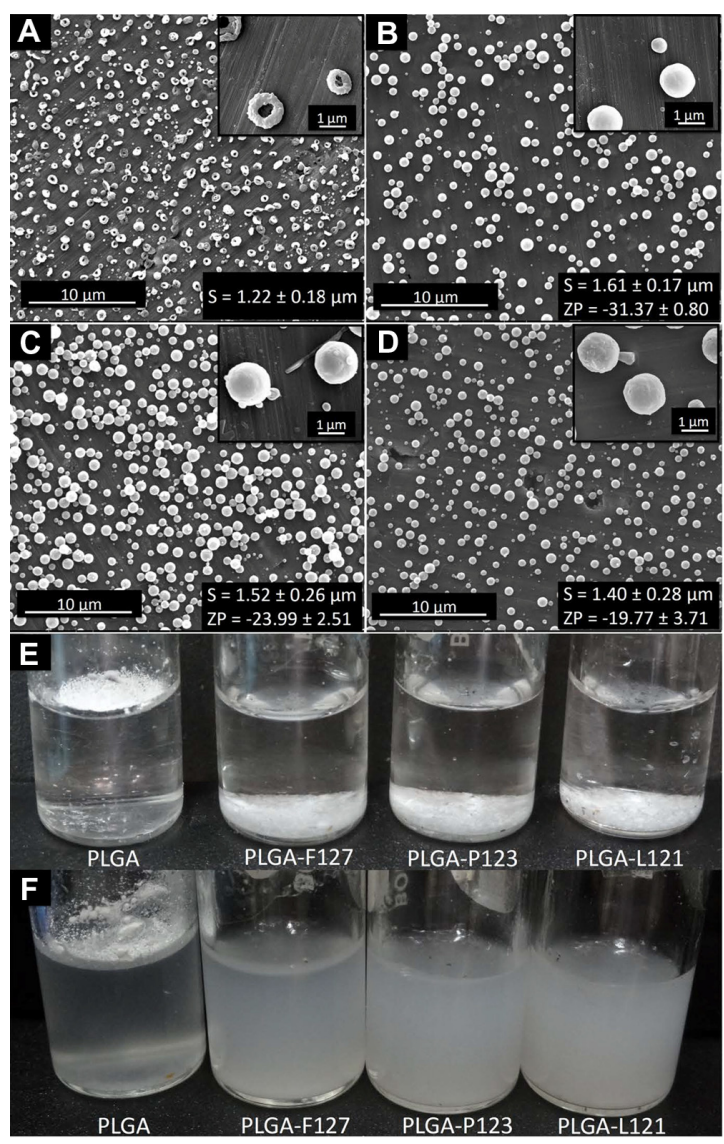

Figure I Scanning electron micrographs of electrosprayed microparticles (A-D), and digital images of PLGA, PLGA-FI 27, PLGA-PI 23, and PLGA-LI 2 I microparticles dispersions in water (E-F). (A) PLGA microparticles. (B) PLGA-Pluronic ${ }^{\circledR}$ FI27 microparticles. (C) PLGA-Pluronic ${ }^{\circledR}$ PI 23 microparticles. (D) PLGA-Pluronic ${ }^{\circledR}$ LI2I microparticles. Low magnification images: scale bar $10 \mu \mathrm{m}$; insets (top right) are high magnification images: scale bar I $\mu \mathrm{m}$; insets (bottom right) $\mathrm{S}$ and ZP represented as mean \pm standard deviation in $\mu \mathrm{m}$ and $\mathrm{mV}$, respectively. (E) Before sonication. (F) After sonication.

Abbreviations: PLGA, poly(lactide-co-glycolide); S, size; ZP, zeta potential.

dispersed in water. As is evident from Figure 1E, PLGA microparticles did not submerge into water because of insufficient wetting, and showed marginal dispersion (Figure 1F) when subjected to high-energy sonication. On the other hand, Pluronic ${ }^{\circledR}$-blended microparticles effortlessly submerged in water (Figure 1E) and, upon sonication, dispersed to form a milky white colloidal suspension (Figure 1F).

These results provide evidence that the blending of PLGA with low concentrations of Pluronic ${ }^{\circledR}$ (F127, P123, or L121) is advantageous as it leads to homogenous, smooth, spherical morphology of microparticles and facilitates the dispersion of microparticles in water.

\section{Influence of Pluronics ${ }^{\circledR}$ on surface properties of microparticles}

Uniform dispersion of PLGA-Pluronic ${ }^{\circledR}$ microparticles in water indicated that surface properties have probably 
been altered as a result of blending. Hence, surface characterization (including measurement of surface charge, surface hydrophobicity, and surface chemistry of blended microparticles) was performed to understand the effect of blending on surface hydrophilization. Since pure PLGA microparticles agglomerated on the surface of water, accurate quantification of surface properties (charge and hydrophobicity) of pure PLGA microparticles was not practicable.

\section{Surface charge and surface hydrophobicity}

The average microparticle size was estimated to be $1.61 \mu \mathrm{m}$, $1.52 \mu \mathrm{m}$, and $1.40 \mu \mathrm{m}$ for PLGA-F127, PLGA-P123, and PLGA-L121 respectively, although the differences were statistically insignificant $(P>0.05)$. The surface charge of a microparticle is an important characteristic as it provides a measure for the particle's suspension stability. The higher the charge (positive or negative) on the particle, the greater the electrostatic repulsion and as a consequence the particle suspension is more stable. From zeta potential measurements it was observed that with an increase in HLB value of the Pluronic ${ }^{\circledR}$ (L121 < P123 < F127) there was a corresponding increase in zeta potential value (negative). The Pluronic ${ }^{\circledR}$ with the highest HLB value (F127) possessed a relatively longer
EO chain length (200 units) and hence had a higher affinity for water ${ }^{31}$ as compared to the Pluronic ${ }^{\circledR}$ with the next highest HLB value (P123, EO = 39 units), which in turn had a higher affinity for water as compared to the Pluronic ${ }^{\circledR}$ with the lowest HLB value (L121, EO = 10 units). The increased association of water (negatively charged hydroxyl groups) with the increase in HLB value resulted in the observed increase in the zeta potential value (negative). A similar trend was observed for surface hydrophobicity, wherein microparticles blended with Pluronic ${ }^{\circledR}$ F127 (HLB-22) showed a lesser adsorption of hydrophobic dye (Rose Bengal) due to a strong interaction with water molecules than Pluronic ${ }^{\circledR}$ L121 (HLB-1) blended microparticles that showed the highest adsorption of dye due to their relatively lesser interaction with water. As is evident from Figure 2, the increase in HLB value of blended Pluronic ${ }^{\circledR}$ (F127 > P123 > L121) led to a decrease in the amount of dye adsorbed which in turn was indicative of a decrease in surface hydrophobicity. The slopes of the linear trend lines $(\mathrm{F} 127=0.10, \mathrm{P} 123=0.14, \mathrm{~L} 121=0.20)$, which is an indirect measure of the surface hydrophobicity of microparticles, were calculated from Figure 2. The results demonstrated that the strategy of blending Pluronics ${ }^{\circledR}$ of varying HLB values allowed for a systematic modulation of surface hydrophobicity as well as surface charge of the electrosprayed microparticles.

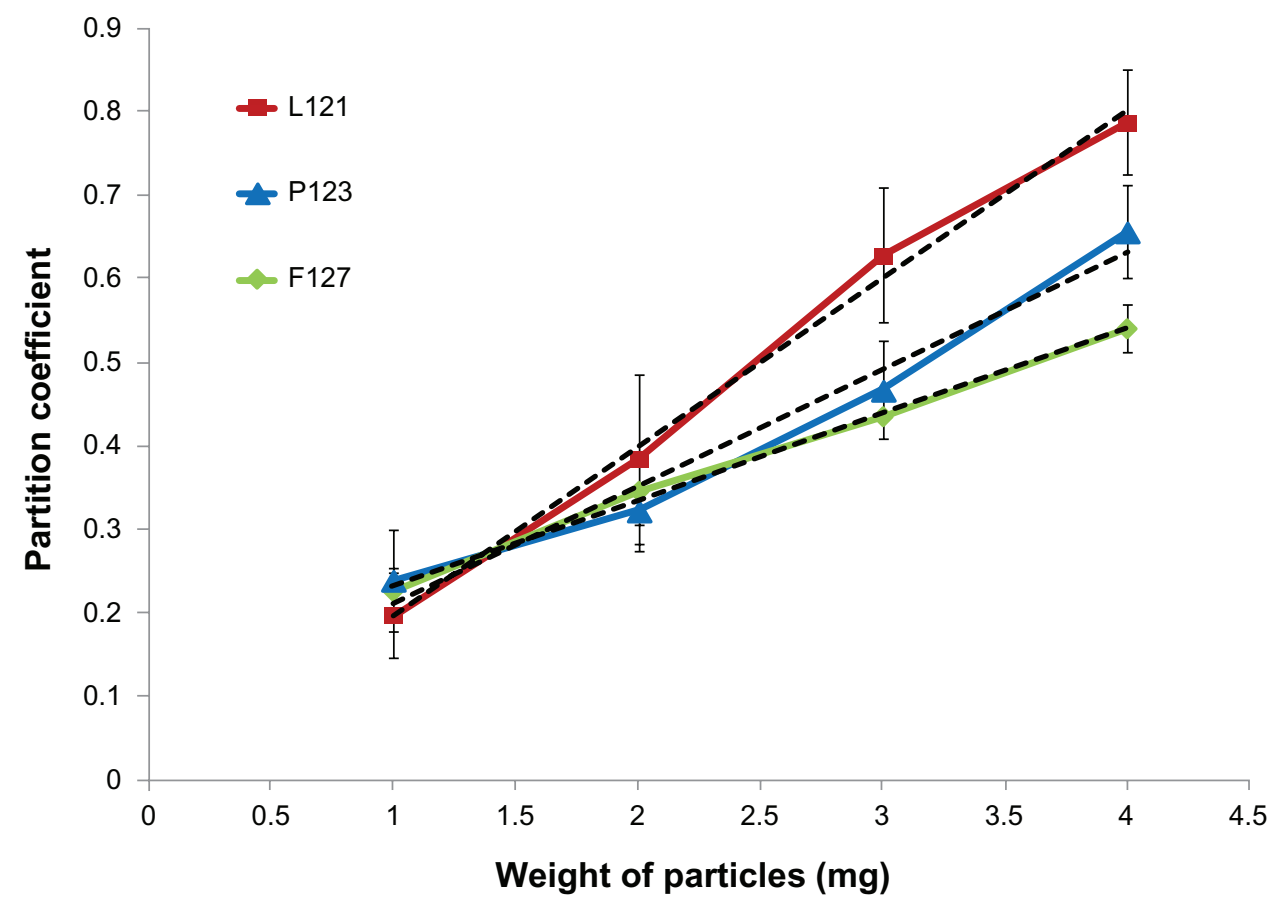

Figure 2 Plot of partition coefficient (determined by Rose Bengal assay) against weight of microparticles.

Notes: Green: PLGA-FI27 ( $R^{2}=0.99, P$ value $=0.00$ I8); blue: PLGA-PI $23\left(R^{2}=0.97, P\right.$ value $\left.=0.0136\right)$; and red: $P L G A-L I 2 I\left(R^{2}=0.99, P\right.$ value $\left.=0.0029\right)$ with corresponding linear trend lines (black dotted lines) for slope determination. For values of $P<0.05$, the difference is statistically significant.

Abbreviations: PLGA, poly(lactide-co-glycolide); $\mathrm{R}^{2}$, Pearson's correlation coefficient. 


\section{Surface chemistry}

XPS analysis was performed to confirm the presence and amount of Pluronic ${ }^{\circledR}$ on the surface of the blended microparticles.

The analysis of XPS C-1s spectra revealed the presence of carbon signals due to four characteristic components present in the blends $-\mathrm{C}-\mathrm{C}, \mathrm{C}-\mathrm{O}, \mathrm{C}-\mathrm{C}-\mathrm{O}$, and $\mathrm{O}=\mathrm{C}-\mathrm{O}$ with peaks at binding energy values of $248.2 \mathrm{eV}, 286.2 \mathrm{eV}, 287.2 \mathrm{eV}$, and $288.9 \mathrm{eV}$, respectively (Figure 3A and B). The presence of Pluronic ${ }^{\circledR}$ on the surface of the microparticles was confirmed by the (2)C $-\mathrm{O}$ peak at $286.2 \mathrm{eV}$ that is specific to Pluronic ${ }^{\circledR}$ and has been reported to be absent in the case of pure PLGA samples. ${ }^{25}$ In order to quantify the amount of Pluronic ${ }^{\circledR}$ present on microparticle surfaces, the intensities of the peaks (values of the atomic percentage composition) of all four components were estimated and the amount of Pluronic ${ }^{\circledR}$ present on the surface was determined using a previously reported method (Equations S1 and S2 in Supplementary materials). ${ }^{32}$

The concentration of Pluronic ${ }^{\circledR}$ was $5 \% \mathrm{w} / \mathrm{w}$ of PLGA and thus the amount of Pluronic ${ }^{\circledR}$ present in the total polymer (Pluronic $^{\circledR}+$ PLGA) was $4.76 \% \mathrm{w} / \mathrm{w}$ (bulk concentration). As is evident from Table 1, the percent mass ratio (MsR) of Pluronic $^{\circledR}$ (concentration on surface) was approximately $32 \%$ (32.8\% for $\mathrm{F} 127,32.5 \%$ for $\mathrm{P} 123$, and $33.0 \%$ for $\mathrm{L} 121$ ). The degree of accumulation $\left(\mathrm{A}_{\mathrm{s}}\right)$ of Pluronic ${ }^{\circledR}$ on the surface, expressed as the ratio of MsR to bulk concentration, was

A<smiles>C=C(C)C(=O)OC(=O)CC(C)(C)C</smiles>

Poly(lactide-co-glycolide)

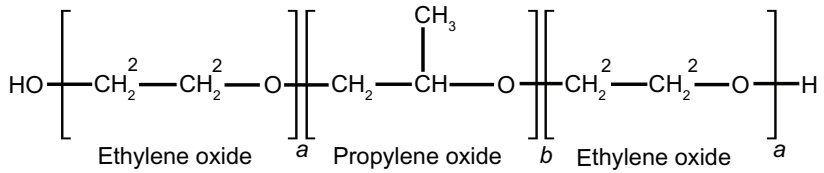

Pluronic $^{\circledR}$

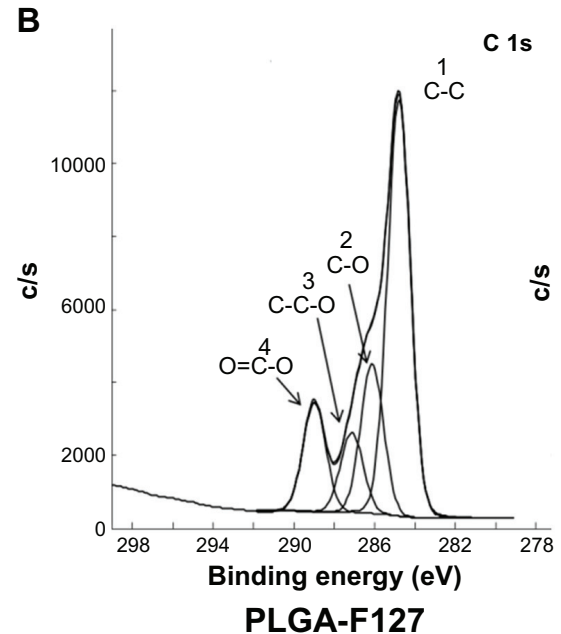

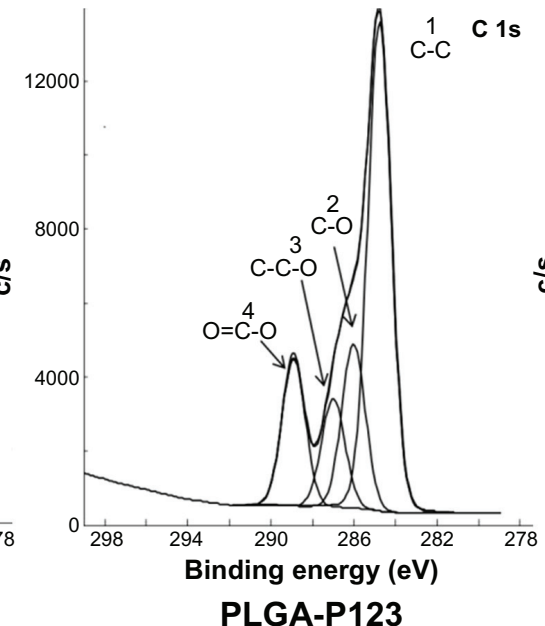

PLGA-P123

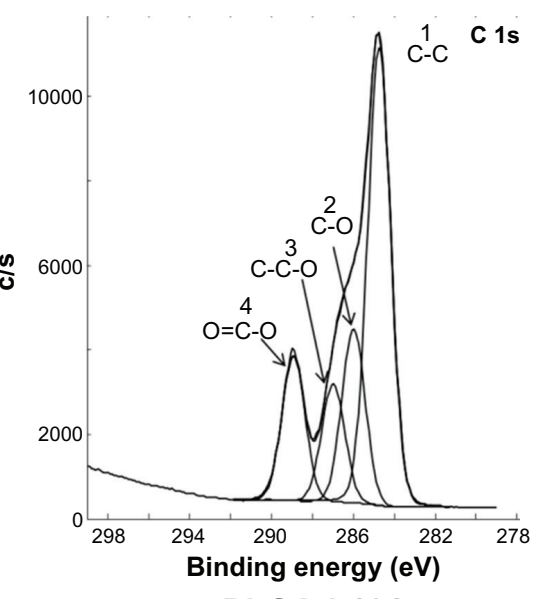

PLGA-L121

c
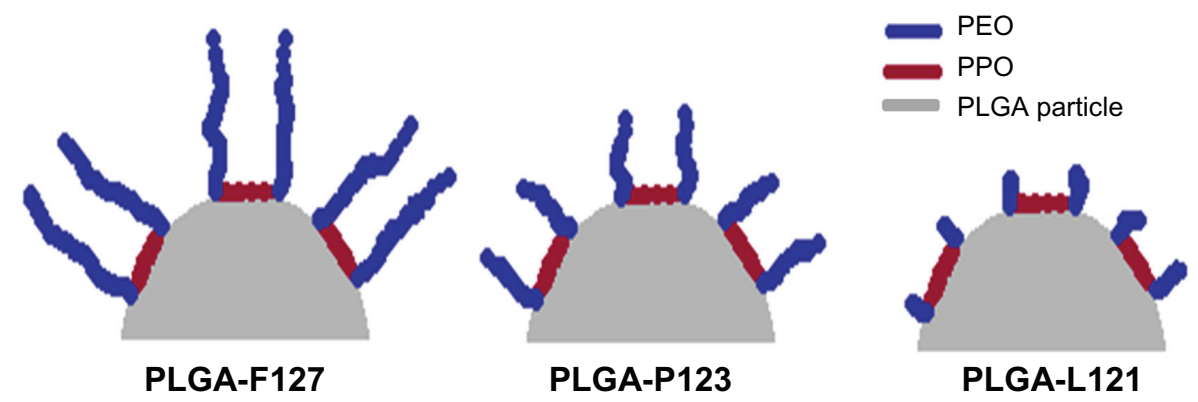

Figure 3 XPS analysis of surface chemistry. (A) Chemical structure of PLGA and Pluronic ${ }^{\circledR}$ representing its monomer units. (B) Deconvoluted C-Is XPS spectra (binding energy versus intensity) of microparticles fabricated from PLGA-FI27, PLGA-PI23 and PLGA-LI2I. (C) Graphic representing differences in EO chains lengths of Pluronic ${ }^{\circledR}$ FI27, Pluronic ${ }^{\circledR}$ PI23, and Pluronic ${ }^{\circledast}$ LI2I on the surface of electrosprayed PLGA-Pluronic ${ }^{\circledR}$ microparticles.

Abbreviations: EO, ethylene oxide; PEO, poly(ethylene oxide); PLGA, poly(lactide-co-glycolide); PPO, poly(propylene oxide); XPS, X-ray photoelectron spectroscopy. 


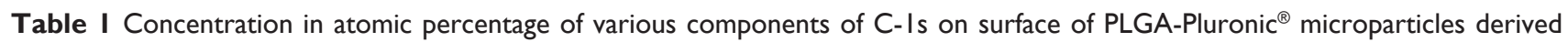
from XPS spectra along with values of monomer ratio, mass ratio, and $A_{s}$

\begin{tabular}{|c|c|c|c|c|c|c|c|}
\hline \multirow[t]{3}{*}{ Particle type } & \multicolumn{7}{|c|}{ Concentration in atomic percentage of C-Is species } \\
\hline & (I)C-C & $(2) \mathrm{C}-\mathrm{O}$ & (3) C-C-O & (4) $O=C-O$ & MnR & $\%$ MsR & $\mathbf{A}_{\mathrm{s}}$ \\
\hline & $284.8 \mathrm{eV}$ & $286.2 \mathrm{eV}$ & $287.2 \mathrm{eV}$ & $288.9 \mathrm{eV}$ & & & \\
\hline PLGA-FI27 & 56.99 & 20.33 & 8.56 & 14.11 & 0.42 & 32.80 & 6.56 \\
\hline PLGA-PI 23 & 56.78 & 19.00 & 8.39 & 15.83 & 0.37 & 32.50 & 6.50 \\
\hline PLGA-LI2I & 54.55 & 20.68 & 8.88 & 15.88 & 0.39 & 33.00 & 6.60 \\
\hline
\end{tabular}

Abbreviations: As, degree of accumulation; MnR, monomer ratio; MsR, mass ratio; PLGA, poly(lactide-co-glycolide); XPS, X-ray photoelectron spectroscopy.

estimated to be $\sim 6.5(6.56,6.50$, and 6.60 for F127, P123, and L121, respectively) which confirmed a high $\mathrm{A}_{\mathrm{s}}$ of Pluronic ${ }^{\circledR}$ on surface of PLGA microparticles.

It was interesting to note that, for the concentrations of Pluronic ${ }^{\circledR}$ that were studied, the values of $\% \mathrm{MsR}$ and $\mathrm{A}_{\mathrm{s}}$ were similar, indicating that the $\mathrm{A}_{\mathrm{s}}$ of Pluronic ${ }^{\circledR}$ on the surface is independent of the type of Pluronic ${ }^{\circledR}$ used. Thus, the XPS data revealed that Pluronic ${ }^{\circledR}$ is preferentially present on the surface and the $\mathrm{A}_{\mathrm{s}}$ is similar irrespective of the type of Pluronic ${ }^{\circledR}$ used. Since $A_{s}$ was similar, the observed differences in hydrophobicity and zeta potential can be attributed to variation in $\mathrm{EO}$ chain length (since PO chain length was approximately constant) as shown in Figure 3C. Further, the dispersion stability observed in Pluronic ${ }^{\circledR}$-blended microparticles can now be explained by the inherent nature of Pluronic ${ }^{\circledR}$ present on the surface to cause electrostatic and steric repulsion. ${ }^{33}$

\section{Conclusion}

This study explored the electrospraying of blends of Pluronic ${ }^{\circledR}$ with PLGA for modulation of the morphology and surface properties of PLGA microparticles. The results from the morphology studies demonstrated that the incorporation of Pluronic $^{\circledR}$ (a polymeric surfactant) led to a drastic change in morphology from doughnut-shaped microparticles for pure PLGA to smooth, spherical microparticles for blended PLGA irrespective of the type of Pluronic ${ }^{\circledR}$ used in the blend. Studies on surface hydrophobicity and surface charge revealed that these surface properties could be systematically modulated by varying the type of Pluronic ${ }^{\circledR}$ used. Therefore, the electrospraying of blends of Pluronic ${ }^{\circledR}$ with PLGA can be a relatively simple, one-step method for modulating morphology and surface properties of PLGA microparticles. Moreover, the work presented exemplifies the versatility of the electrospraying process as it can be used for both modulating morphology and surface properties of microparticles.

Although this study was performed using high-, intermediate-, and low-HLB value Pluronics ${ }^{\circledR}$, the availability of a wide range of Pluronics ${ }^{\circledR}$ allows for the possibility of precise control of the surface properties of electrosprayed particles. Similarly, the strategy of blending Pluronic ${ }^{\circledR}$ with hydrophobic polymers for the modulation of surface properties was demonstrated using the PLGA system; it is speculated that the strategy could be extrapolated to other hydrophobic polymers as well.

Finally, since surface properties such as charge and hydrophobicity of microparticles have direct implications on protein adsorption and downstream cell interaction, it is expected that this study will pave the way for enabling improved cell interaction, including internalization.

\section{Acknowledgments}

The authors would like to acknowledge the Department of Biotechnology (DBT) and the Indian Council of Medical Research (ICMR), Government of India for funding this research work. The authors would like to thank Physical Electronics, USA for performing XPS analysis and the ACMS/DST unit on Nanoscience, Indian Institute of Technology Kanpur (IITK) for SEM analysis. AS acknowledges IITK for funding. DSK acknowledges the "Batch of 1970 Research Fellowship."

\section{Disclosure}

The authors report no conflicts of interest in this work.

\section{References}

1. Slomkowski S, Basinska T. Polymer nano- and microparticle based systems for medical diagnostics. Macromol Symp. 2010;295(1):13-22.

2. Edwards DA, Hanes J, Caponetti G, et al. Large porous particles for pulmonary drug delivery. Science. 1997;276(5320):1868-1871.

3. Malyala P, O'Hagan DT, Singh M. Enhancing the therapeutic efficacy of $\mathrm{CpG}$ oligonucleotides using biodegradable microparticles. Adv Drug Deliver Rev. 2009;61(3):218-225.

4. Kwon YJ, James E, Shastri N, Fréchet JM. In vivo targeting of dendritic cells for activation of cellular immunity using vaccine carriers based on pH-responsive microparticles. Proc Natl Acad Sci U S A. 2005; 102(51):18264-18268.

5. Langer R. New methods of drug delivery. Science. 1990;249(4976): $1527-1533$.

6. Baumes JM, Gassensmith JJ, Giblin J, et al. Storable, thermally activated, near-infrared chemiluminescent dyes and dye-stained microparticles for optical imaging. Nat Chem. 2010;2(12):1025-1030. 
7. Alexis F, Pridgen E, Molnar LK, Farokhzad OC. Factors affecting the clearance and biodistribution of polymeric nanoparticles. Mol Pharm. 2008;5(4):505-515.

8. Doshi N, Mitragotri S. Designer biomaterials for nanomedicine. $A d v$ Funct Mater. 2009;19(24):3843-3854.

9. Wang FJ, Wang CH. Sustained release of etanidazole from spray dried microspheres prepared by non-halogenated solvents. J Control Release. 2002;81(3):263-280.

10. Gratton SE, Ropp PA, Pohlhaus PD, et al. The effect of particle design on cellular internalization pathways. Proc Natl Acad Sci USA. 2008;105(33):11613-11618.

11. Arnida, Malugin A, Ghandehari H. Cellular uptake and toxicity of gold nanoparticles in prostate cancer cells: a comparative study of rods and spheres. J Appl Toxicol. 2010;30(3):212-217.

12. Alexander L, Dhaliwal K, Simpson J, Bradley M. Dunking doughnuts into cells - selective cellular translocation and in vivo analysis of polymeric micro-doughnuts. Chem Commun. 2008;(30): 3507-3509.

13. Hamad I, Al-Hanbali O, Hunter AC, Rutt KJ, Andresen TL, Moghimi SM. Distinct polymer architecture mediates switching of complement activation pathways at the nanosphere-serum interface: implications for stealth nanoparticle engineering. ACS Nano. 2010;4(11):6629-6638.

14. Aggarwal P, Hall JB, McLeland CB, Dobrovolskaia MA, McNeil SE. Nanoparticle interaction with plasma proteins as it relates to particle biodistribution, biocompatibility and therapeutic efficacy. Adv Drug Deliv Rev. 2009;61(6):428-437.

15. Giljohann DA, Seferos DS, Patel PC, Millstone JE, Rosi NL, Mirkin CA. Oligonucleotide loading determines cellular uptake of DNA-modified gold nanoparticles. Nano Lett. 2007;7(12):3818-3821.

16. Nel AE, Mädler L, Velegol D, et al. Understanding biophysicochemical interactions at the nano-bio interface. Nat Mater. 2009;8(7):543-557.

17. Chakraborty S, Liao IC, Adler A, Leong KW. Electrohydrodynamics: a facile technique to fabricate drug delivery systems. Adv Drug Deliv Rev. 2009;61(12):1043-1054.

18. Valo H, Peltonen L, Vehviläinen S, et al. Electrospray encapsulation of hydrophilic and hydrophobic drugs in poly(L-lactic acid) nanoparticles. Small. 2009;5(15):1791-1798.

19. Fenn JB, Mann M, Meng CK, Wong SF, Whitehouse CM. Electrospray ionization for mass spectrometry of large biomolecules. Science. 1989; 246(4926):64-71.

20. Yao J, Lim LK, Xie J, Hua J, Wang CH. Characterization of electrospraying process for polymeric particle fabrication. J Aerosol Sci. 2008;39(11):987-1002.
21. Fantini D, Zanetti M, Costa L. Polystyrene microspheres and nanospheres produced by electrospray. Macromol Rapid Commun. 2006;27(23):2038-2042.

22. Almería B, Deng W, Fahmy TM, Gomez A. Controlling the morphology of electrospray-generated PLGA microparticles for drug delivery. J Colloid Interface Sci. 2010;343(1):125-133.

23. Shive MS, Anderson JM. Biodegradation and biocompatibility of PLA and PLGA microspheres. Adv Drug Deliv Rev. 1997;28(1):5-24.

24. Kamiya H, Iijima M. Surface modification and characterization for dispersion stability of inorganic nanometer-scaled particles in liquid media. Sci Technol Adv Mater. 2010;11(4):044304.

25. Vasita R, Mani G, Agrawal CM, Katti DS. Surface hydrophilization of electrospun PLGA micro-/nano-fibers by blending with Pluronic ${ }^{\circledR}$ F-108. Polymer. 2010;51(16):3706-3714.

26. Santander-Ortega MJ, Jódar-Reyes AB, Csaba N, Bastos-González D, Ortega-Vinuesa JL. Colloidal stability of Pluronic ${ }^{\circledR}$ F68-coated PLGA nanoparticles: a variety of stabilisation mechanisms. J Colloid Interface Sci. 2006;302(2):522-529.

27. Batrakova EV, Kabanov AV. Pluronic ${ }^{\circledR}$ block copolymers: evolution of drug delivery concept from inert nanocarriers to biological response modifiers. J Control Release. 2008;130(2):98-106.

28. Kabanov AV, Alakhov VY. Pluronic ${ }^{\mathbb{B}}$ block copolymers in drug delivery: from micellar nanocontainers to biological response modifiers. Crit Rev Ther Drug Carrier Syst. 2002;19(1):1-72.

29. Alakhova DY, Rapoport NY, Batrakova EV, et al. Differential metabolic responses to Pluronic ${ }^{\circledR}$ in MDR and non-MDR cells: a novel pathway for chemosensitization of drug resistant cancers. $J$ Control Release. 2010;142(1):89-100.

30. Singh J, Pandit S, Bramwell VW, Alpar HO. Diphtheria toxoid loaded poly-(epsilon-caprolactone) nanoparticles as mucosal vaccine delivery systems. Methods. 2006;38(2):96-105.

31. Marinova KG, Alargova RG, Denkov ND, et al. Charging of oil-water interfaces due to spontaneous adsorption of hydroxyl ions. Langmuir. 1996;12(8):2045-2051.

32. Kiss E, Bertóti I, Vargha-Butler EI. XPS and wettability characterization of modified poly(lactic acid) and poly(lactic/glycolic acid) films. J Colloid Interface Sci. 2002;245(1):91-98.

33. Gotchev G, Kolarov T, Khristov K, Exerowa D. Electrostatic and steric interactions in oil-in-water emulsion films from Pluronic ${ }^{\circledR}$ surfactants. Adv Colloid Interface Sci. 2011;168(1-2):79-84. 


\section{Supplementary material}

The concentration of Pluronic ${ }^{\circledR}$ was expressed as a ratio of $\%(2) \mathrm{C}-\mathrm{O}$ specific to Pluronic ${ }^{\circledR}$ to $\%(4) \mathrm{O}=\mathrm{C}-\mathrm{O}$ specific to poly(lactide-co-glycolide) (PLGA). A monomer of Pluronic ${ }^{\circledR}$ contains two ether carbons contributing to peak (2)C-O, hence the intensity values were multiplied by 0.5 to arrive at actual Pluronic ${ }^{\circledR}$ content,

$$
\text { Monomer ratio } \mathrm{MnR}=\frac{0.5 \times \%(2) \mathrm{C}-\mathrm{O}}{0.5 \times \%(2) \mathrm{C}-\mathrm{O}+\%(3) \mathrm{O}=\mathrm{C}-\mathrm{O}}
$$

where, $\%(2) \mathrm{C}-\mathrm{O}$ is the atomic $\%$ of $\mathrm{C}-\mathrm{O}$ at $286.2 \mathrm{eV}$ due to Pluronic ${ }^{\circledR}$ and $\%(3) \mathrm{O}=\mathrm{C}-\mathrm{O}$ is the atomic $\%$ of $\mathrm{O}=\mathrm{C}-\mathrm{O}$ at $288.9 \mathrm{eV}$ due to PLGA.

Monomer ratio (MnR) can be expressed as mass ratio (MsR) by using Equation S2,

$\%$ mass ratio $\mathrm{MsR}=\frac{0.5 \times \%(2) \mathrm{C}-\mathrm{O} \times \mathrm{Xi}}{0.5 \%(2) \mathrm{C}-\mathrm{O} \times \mathrm{Xi}+\%(3) \mathrm{O}=\mathrm{C}-\mathrm{O} \times \mathrm{Y}}$

where, $\mathrm{Y}=$ molecular weight of PLGA 85:15 and $\mathrm{Xi}=$ molecular weight of Pluronic ${ }^{\circledR}$ from Table S1.
Table SI Molecular weight of monomers for PLGA and Pluronic $^{\circledR}$

\begin{tabular}{ll}
\hline Polymer & $\begin{array}{l}\text { Monomer molecular } \\
\text { weight (Mo) }\end{array}$ \\
\hline PLA & 72 \\
PLGA 85:I5 (Y) & 69.9 \\
PGA & 58 \\
PEO & 44 \\
PPO & 58 \\
Pluronic ${ }^{\circledR}$-FI27 (\%EO 75.5I + \% PO 24.49) (XI) 47.42 \\
Pluronic ${ }^{\circledR}$-PI23 (\%EO 36.23 + \% PO 63.77) (X2) 52.93 \\
Pluronic ${ }^{\circledR}$-LI2I (\%EO I2.82 + \% PO 87.18) (X3) 56.20 \\
\hline
\end{tabular}

Notes: $Y, X I, X 2$, and $X 3$ were as used in Equations $S 1$ and S2.

Abbreviations: Mo, molecular weight; PEO, poly(ethylene oxide); PGA, polyglycolic acid; PLA, polylactic acid; PLGA, poly(lactide-co-glycolide); PPO, poly(propylene oxide).
International Journal of Nanomedicine

\section{Publish your work in this journal}

The International Journal of Nanomedicine is an international, peerreviewed journal focusing on the application of nanotechnology in diagnostics, therapeutics, and drug delivery systems throughout the biomedical field. This journal is indexed on PubMed Central, MedLine, CAS, SciSearch ${ }^{\circledR}$, Current Contents ${ }^{\circledR} /$ Clinical Medicine,

\section{Dovepress}

Journal Citation Reports/Science Edition, EMBase, Scopus and the Elsevier Bibliographic databases. The manuscript management system is completely online and includes a very quick and fair peer-review system, which is all easy to use. Visit http://www.dovepress.com/ testimonials.php to read real quotes from published authors. 